
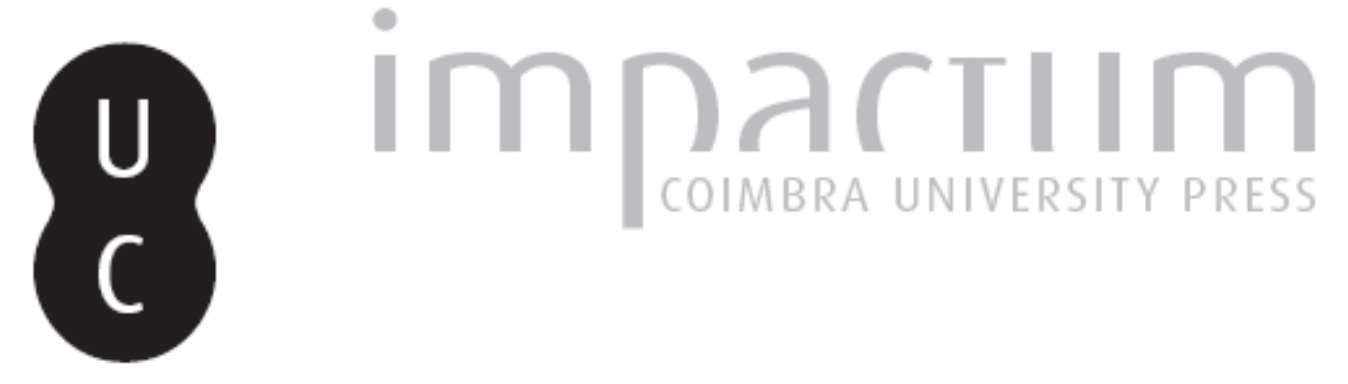

\title{
Perspectivas e sucessos dos estudos sobre o petrarquismo
}

Autor(es): $\quad$ Gigliucci, Roberto

Publicado por: Imprensa da Universidade de Coimbra

URL persistente:

URl:http://hdl.handle.net/10316.2/42681

DOI:

DOI:https://doi.org/10.14195/0870-8584_1_4

Accessed : $\quad$ 26-Apr-2023 12:21:08

A navegação consulta e descarregamento dos títulos inseridos nas Bibliotecas Digitais UC Digitalis, UC Pombalina e UC Impactum, pressupõem a aceitação plena e sem reservas dos Termos e Condições de Uso destas Bibliotecas Digitais, disponíveis em https://digitalis.uc.pt/pt-pt/termos.

Conforme exposto nos referidos Termos e Condições de Uso, o descarregamento de títulos de acesso restrito requer uma licença válida de autorização devendo o utilizador aceder ao(s) documento(s) a partir de um endereço de IP da instituição detentora da supramencionada licença.

Ao utilizador é apenas permitido o descarregamento para uso pessoal, pelo que o emprego do(s) título(s) descarregado(s) para outro fim, designadamente comercial, carece de autorização do respetivo autor ou editor da obra.

Na medida em que todas as obras da UC Digitalis se encontram protegidas pelo Código do Direito de Autor e Direitos Conexos e demais legislação aplicável, toda a cópia, parcial ou total, deste documento, nos casos em que é legalmente admitida, deverá conter ou fazer-se acompanhar por este aviso.

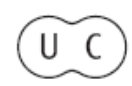




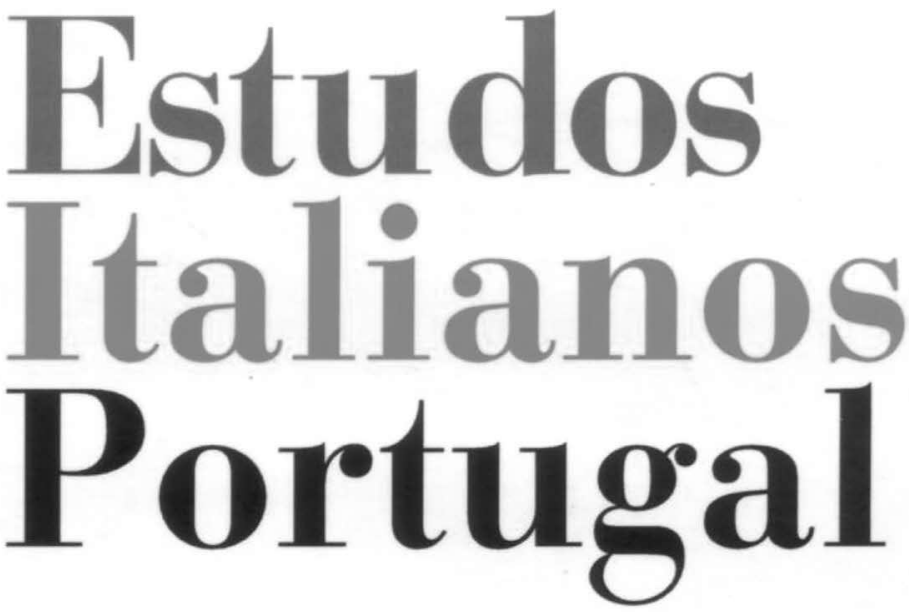

Instituto

Italiano

de Cultura

em Portugal

Nova Série

$\mathbf{N}^{\circ} \mathbf{1}$

2006 
PERSPECTIVAS E SUCESSOS DOS ESTUDOS SOBRE O PETRARQUISMO*

Roberto Gigliucci

EM TORNO DA OCASIÃO OFERECIDA pelo sétimo centenário do nascimento de Francesco Petrarca, multiplicaram-se as reflexões sobre o fenómeno do petrarquismo: simpósios, ensaios, seminários, encontros europeus e extra-europeus fizeram o ponto da situação. Em Itália, um grupo de trabalho coordenado por Amedeo Quondam organizou uma série de colóquios, começando pelo dedicado a Petrarca nel Novecento italiano ${ }^{1}$, que, cronologicamente, pela sua matéria se poderia considerar uma última etapa. O século que acabou de se concluir foi definido como "o mais dantesco da história", o mais plurilinguista e "infernal", "catabático", corpóreo e purulento, dizimado por guerras nunca vistas e, mais do que isso, por uma violência sistematicamente exaltada. Contudo, a voz de Petrarca, a sua linguagem emblemática e absoluta, depois da experiência de Mallarmé e de Valéry, desfrutaram um relevo essencial na Itália do hermetismo que se propagou até ao complexo petrarquismo de Zanzotto. Sabe-se, pois, que o petrarquismo do século XX é um petrarquismo híbrido, embutido numa matéria outra, a ponto de poder conviver com heresias históricas que lhe são internas, quando não com formas de antipetrarquismo.

* Tradução de Rita Marnoto.

1 Un'altra storia. Petrarca nel Novecento italiano, a cura di Andrea Cortellessa, Roma, Bulzoni, 2005. 
Significativa, nesse sentido, é a posição do Montale que, pelo menos em algumas sequências da sua obra (em Finisterre, mas já anteriormente nos Mottetti) declara ter activado um seu 'petrarquismo'2. Em Montale, podemos reconhecer um dantismo de palavras e um petrarquismo de emblemas. Como naquela tradição metafisica que do Maneirismo-Barroco vai até Baudelaire e daí até Eliot e Rilke, a recuperação do real, do matério-objectual e até do prosaico 'moderno', é feita à custa da reintegração daqueles dados empíricos e opacos numa dimensão de lampejo metafísico com significação meta-empírica. O regresso ao plano físico comporta, pois, uma assunção metafísica a posteriori. Assim se identifica uma heresia mais ou menos interna ao petrarquismo de longa duração. É no século XX que essas questões vêm à liça. Por um lado, o petrarquismo da pureza, das palavras sem corpo de referentes, dos emblemas puros (flores, frondes, ervas, sombras, antros, ondas, etc.), linguagem de eleição não só por via de um seu monolinguismo, como, e sobretudo, por via de uma abstracção ideal. Esse é o modo poético petrarquista que leva a Mallarmé e daí até Valéry e Guillén e depois até um certo hermetismo italiano. Por outro lado, o modo poético do "petrarquismo metafisico", ou poesia metafisica tout court, apesar de ter origem numa costela do Canzoniere, talvez marginal, como a própria celebração metafísica de dados objectuais menores, por exemplo, uma luva de Laura. Poderia mesmo dizer que, da luva de Laura descendem, quem sabe, os amuletos de Clizia, mas também os leques de Mallarmé. É assim que dos cabelos de Laura decorrem as chevelures de Baudelaire e de Mallarmé, dois modelos antitéticos da poesia moderna. Em suma, no paradigma petrarquesco está tudo, como no livro originário, como numa

2 Roberto Gigliucci, Petrarchismo metafisico e Montale, "Sincronie", 8, 2004, 15, pp. 77-92, posteriormente desenvolvido no volume, Realismo metafisico e Montale, Roma, Nuova Cultura, 2005. bíblia. Como se o petrarquismo, sobretudo o do século XX, fosse tão forte (e desfigurado), a ponto de poder conter em si também o dantismo. E, contudo, estamos a falar de um petrarquismo que passou através da metamorfose barroca (nas origens do moderno). Assim é para Ungaretti, apaixonado leitor de Petrarca, a quem consagra magníficos ensaios, mas sobretudo extraordinário protagonista de uma complexa simbiose com as poéticas barrocas. O petrarquismo ungaretiano vai da pureza das suas origens às mais deslumbrantes incrustações gongóricas e metafísicas, atravessando a lírica de Shakespeare, para com elas compor um opus verdadeiramente alquímico no qual vive, mais do que o historiador das formas, o poeta. Tudo isto nos deve levar, como é óbvio, a precavermo-nos da divisão, talhada com demasiada secura militar, de duas facções não comunicantes, uma pura, outra fisico-metafísica. Trata-se de dois modos poéticos, já o dissemos, que como tal podem conhecer infinitos conluios e infinitos cambiantes.

Falou-se do Barroco. A segunda etapa dos congressos ideados por Quondam intitulou-se, precisamente, Petrarca in Barocco $^{3}$. O prefácio ao volume das actas, por ele assinado, contém uma rica introdução às mais recentes pesquisas sobre o petrarquismo, considerado como fenómeno penetrante de longue durée que acompanha toda a cultura do classicismo no Antigo Regime, continuando a modelar a língua poética pelo menos até Leopardi. O petrarquismo é, sobretudo no século XVI, forma de comunicação das classes elevadas, língua do gentil-homem que tem de mostrar que a domina para participar na cultura comum. Resumindo, é um petrarquismo de koine, destinado não só a sancionar a tão necessária reforma linguística, na idade da imprensa, mas também a proporcionar a fruição da sua langue por parte das

3 Petrarca in Barocco. Cantieri petrarchistici. Due seminari romani, a cura di Amedeo Quondam, Roma, Bulzoni, 2004. 
pessoas 'civilizadas', por parte do homem e da mulher de corte, por parte de quem não renuncia à civil conversazione. Não por acaso sofreu tão significativo incremento, nos últimos tempos, o estudo do panorama das antologias poéticas petrarquistas do século $\mathrm{XVI}^{4}$, um verdadeiro boom editorial iniciado com a experiência pioneira das Rime diverse organizadas por Lodovico Domenichi em 1545 para o editor Giolito. Essas antologias eram autênticos espelhos da sociedade mundano-literária do tempo, verdadeiros jardins da conversação de nível elevado entre poetas de profissão e poetas diletantes. Todavia, são precisamente os poetas de ocasião que representam, sociologicamente, a fatia mais interessante, documento da necessidade do dever estar lá, do 'presencialismo', por assim dizer, da sociedade renascentista. Além disso, também poetas ultraprofissionais, como um Bembo ou um Della Casa, eram protagonistas da vida sócio-literária do tempo.

A terceira etapa do percurso dos congressos foi assinalada pela indagação acerca do petrarquismo aquém dos espaços da lírica, nos outros géneros literários. Uma exploração pelos Territori del petrarchismo ${ }^{5}$, da comédia à tragédia, da épica à fábula pastoril, etc. Reflexos de um momento crucial da história da poesia de amor europeia encontram-se, em particular, na pastoral quinhentista ${ }^{6}$. Ao embutir numa fabula a

\footnotetext{
${ }^{4}$ Rime diverse di molti eccellentissimi autori (Giolito 1545), a cura di Franco Tomasi e Paolo Zaja, Torino, RES, 2001; "I più vaghi e i più soavi fiori". Studi sulle antologie di lirica del Cinquecento, a cura di Monica Bianco ed Elena Strada, Alessandria, dell'Orso, 2001; M. L. Cerrón Puga, Materiales para la construcción del canon petrarquista: las antologías de "Rime" (libri I-IX), "Critica del testo", 2, 1999, 1 (n. monogr. L'Antologia poetica), pp. 249-290; Amedeo Quondam, Il naso di Laura. Lingua e poesia lirica nella tradizione del Classicismo, Ferrara-Modena, ISR-Panini, 1991, etc.

${ }^{5}$ I territori del petrarchismo. Frontiere e sconfinamenti, a cura di Cristina Montagnani, Roma, Bulzoni, 2005.

${ }^{6}$ Remeto para o meu, Giù verso l'alto. Luoghi e dintorni tassiani, Manziana, Vecchiarelli, 2004.
}

'cena' lírica, que a partir de Petrarca é dolorosa, trágica, desastrosa, a pastoral inverte-lhe o sentido, alterando o seu desfecho, o qual, de triste, se faz alegre (excepção feita a Giraldi Cinzio), ao mesmo tempo que leva a cabo uma crítica corrosiva ao modelo do amor infeliz. Essa 'cena primária' da poesia de amor, que se desenrola nos confins do teatro psíquico do poeta, quando se faz cena teatral na Arcádia confirma o carácter trágico da falta de correspondência amorosa, condenando aquela dispersão autodestrutiva que paradoxalmente se auto-exalta através da dor. Verdadeiro amor é aquele que reverte sobre uma alteridade que retribui, não o que fica confinado à voluptas dolendi infinita e circular do sujeito. Em suma, a fábula pastoril responde ao petrarquismo reforçando o seu carácter insubstituível no plano linguístico, mas destruindo, com o happy ending, o desespero que o nutre de mortificação e revivificação, o circuito de nevrose de corte donde quer sair. Eis como essa fundamental 'descoberta' do tragicómico assinala, a partir de Guarini, um outro passo em direcção à modernidade através da intersecção de géneros e estilos, ou seja, a um nível mais profundo, através de uma aproximação à substancial ambiguidade do real, num percurso que conduz, via Barroco, por Metastasio, Da Ponte, Mozart, pela ópera semi-séria, pelo romance, pelo drama burguês e, finalmente, por Pirandello e pela complexidade do humorismo.

Um ulterior encontro foi o dedicado ao Petrarchismo nel Settecento e nell'Ottocento, cujas actas ainda se encontram no prelo $^{7}$. O petrarquismo arcádico erige-se em fenómeno de regresso ao passado, ultrapassando o pretérito mais recente, ou seja, o século XVII. Todavia, a experiência lírica do século XVIII não pode deixar de ser compreendida à luz das novidades e das invenções do século precedente. Encontrar

\footnotetext{
7 Também editado em Roma, Bulzoni, a cura di Sandro Gentili e Luig Trenti.
} 
o Barroco na Arcádia, seguindo as pisadas de Calcaterra, significa também descobrir no petrarquismo arcádico as formas da 'modernidade' que articulam e actualizam um processo já secular. A experiência complexa que vai de Rolli a Parini, com todas as suas articulações internas, continua a ter por pressuposto fundador o estetismo do moderno, a beleza do real na sua transfiguração mítico-simbólica. A assunção de dados da realidade (um coche, uma paisagem urbana, um teatro, o ritual do café, do gelado ou do chocolate, a queda do cavalo de uma senhora nobre, etc.), no cosmos mítico e metafisico da beleza significante, é um modo de conceber a poesia, e portanto o petrarquismo, com as suas codificações $\mathrm{e}$ as suas heresias internas, que aproxima dos mais variados modos um Parini a um Foscolo e assim por diante, até Carducci e D'Annunzio. Verdadeira nova descontinuidade, nesse sentido, é a representada por um Pascoli mas o discurso sobre o seu petrarquismo é tão subtil e delicado que merecia ser verdadeiramente aprofundado em estudo específico.

A série de congressos coordenada por Quondam culminou com o grande congresso de 2004, em Bolonha, Il petrarchismo: un modello di poesia per l'Europa, cujas actas se encontram em preparação ${ }^{8}$. Uma grande empresa, dividida em sessões plenárias e paralelas, em cujo âmbito a multiplicação de horizontes de pesquisa foi, programaticamente, riquíssima. Algumas linhas de investigação mantiveram-se inabaláveis. Uma delas é a perspectiva europeia, fruto da qual só se pode ler a história do petrarquismo analisando a sua complexidade e as suas capacidades de inclusão, com transplantes em terras francesas, ibéricas, inglesas, etc. A imagem falsamente homogénea do nosso petrarquismo do século XVI ficará melhor ilustrada, na sua efectiva pluralidade, com o conhecimento, além do mais, da diversidade da sua recepção

${ }^{8}$ A cura di Amedeo Quondam, Gian Mario Anselmi, Floriana Calitti, Loredana Chines, Roberto Gigliucci, Paola Vecchi Galli, Roma, Bulzoni. no estrangeiro, com a complexidade do classicismo, dos diversos maneirismos, da hibridação dos modelos, das declinações metafísicas, conceptistas, erótico-canoras, madrigalescas, etc. Uma outra linha de método que dominou o congresso foi a interdisciplinaridade e, sobretudo, o propósito de estabelecer relações de colaboração e confronto entre literatos e musicólogos. A difusão do madrigal e da poesia para música entre os séculos XVI e XVII, até ao boom editorial de tipologias antológicas específicas, como o Gareggiamento poetico de $1611^{9}$, deve ser perscrutado por literatos que não renunciem a sinergias com musicólogos. O petrarquismo musical é um dado sócio-antropológico perfeitamente complementar do puramente literário.

Naturalmente que, por ocasião do centenário, toda a Europa foi teatro de simpósios sobre Petrarca e o petrarquismo, desde o seu extremo ocidente, onde, em Coimbra, teve lugar um requintado encontro de estudo coordenado por Rita Marnoto ${ }^{10}$, até à oriental Varsóvia, onde Piotr Salwa dirigiu um fervilhante congresso multilingue ${ }^{11}$. Com efeito, a Europa, ao longo da sua história, sempre encontrou no petrarquismo uma linguagem poética comum, uma cepa identitária a partir da qual foram germinando individualidades nacionais, cujos produtos, ao circularem, renovaram e hibridaram também a própria poesia italiana. Aliás, a força do petrarquismo não foi tirânica, se se configurou como um sistema linguístico-ideológico tão tolerante que

\footnotetext{
9 Acerca do qual, Alessandro Martini, Ritratto del madrigale poetico fra Cinque e Seicento, "Lettere italiane", 4, 1981, pp. 529-548.

10 Cujas actas foram publicadas: Petrarca 700 anos, coordenação de Rita Marnoto, Coimbra, Instituto de Estudos Italianos da Faculdade de Letras da Universidade de Coimbra, 2005. Não se deixe de ver, também de Rita Marnoto, O petrarquismo português do Renascimento e do Maneirismo, Universidade de Coimbra, 1997.

11 La tradizione del Petrarca e l'unità della cultura europea, Varsóvia, 27-30 de Maio de 2004, com actas no prelo.
} 
conseguiu incluir as mais problemáticas diferenças. O êxito do século XX, como dissemos, é representativo dessa história: no caldeirão oficinal do Novecento, o petrarquismo manteve uma identidade plural que, porquanto desfigurada, se faz ainda mais lancinante. A ponto de se poder dizer que a poesia, na Europa, é o petrarquismo.

Também a actividade editorial, pelo que diz respeito a textos petrarquistas, assinalou notáveis incrementos nos anos mais recentes. Limitando-nos ao domínio da casa-mãe da italianística, eis um elenco (obviamente não exaustivo!) de alguns títulos de relevo publicados nos últimos dez anos:

- Bernardo Tasso, Rime, 2 vol., a cura di Domenico Chiodo e Vercingetorige Martignone, Torino, Res, 1995.

- Dragonetto Bonifacio, Rime, a cura di Raffaele Girardi, Fasano, Schena, 1995.

- Veronica Gambara, Le rime, a cura di Alan Bullock, Firenze, Olschki, 1995.

- Rime de gli Academici Eterei, a cura di Ginetta Auzzas e Manlio Pastore Stocchi, introduz. di Antonio Daniele, Padova, CEDAM, 1995.

- Veronica Franco, Rime, a cura di Stefano Bianchi, Milano, Mursia, 1995.

- Rimatori politici ed erotici del Cinquecento genovese, a cura di Stefano Verdino, Genova, Costa \& Nolan, 1996.

- Versi et regole della nuova poesia toscana. In Roma per Antonio Blado d'Asola. 1539, a cura di Massimiliano Mancini, Roma, Vecchiarelli, 1996.

- Luigi Tansillo, Canzoniere edito ed inedito, a cura di Erasmo Pèrcopo, [1926], n. ed., a cura di Tobia R. Toscano, Napoli, Liguori, 1996 (com recurso a manuscritos autógrafos pertença do editor).

- Baldassarre Olimpo da Sassoferrato, Gloria, a cura di Clito Bruschi, Sassoferrato, Centro Culturale "Baldassarre Olimpo", 1996 (o mesmo editor e o mesmo crítico publicaram, em 1993, o Linguaccio).
- Ascanio Pignatelli, Rime, a cura di Maurizio Slawinski, Torino, Res, 1996.

- Diego Sandoval Di Castro, Rime, a cura di Tobia R. Toscano, Roma, Salerno, 1997.

- Remigio Nannini, Rime, a cura di Domenico Chiodo, Torino, Res, 1997.

- Giacomo Zane, Rime, a cura di Giovanna Rabitti, Padova, Antenore, 1997.

- Vittoria Colonna, Sonetti. In morte di Francesco Ferrante d'Avalos Marchese di Pescara (Edizione del ms. XIII, G, 43 della Biblioteca Nazionale di Napoli), a cura di Tobia Toscano, Milano, Editoriale Giorgio Mondadori, 1998.

- Orsatto Giustinian, Rime, a cura di Ranieri Mercatanti, Firenze, Olschki 1998.

- Michelangelo Buonarroti, Rime, a cura di M. Residori, Milano, Mondadori, 1998.

- Giuseppina La Face Bianconi, Antonio Rossi, Le rime di Serafino Aquilano in musica, Firenze, Olschki, 1999.

- Berardino Rota, Rime, a cura di Luca Milite, Parma, Guanda, 2000.

- La lirica rinascimentale, a cura di Roberto Gigliucci, Introduz. di Jacqueline Risset, Roma, Poligrafico e Zecca dello Stato, 2000.

- Isabella di Morra, Rime, a cura di Maria Antonietta Grignani, Roma, Salerno, 2000 (amplia e reelabora o seu precedente contributo, Per Isabella di Morra, "Rivista di letteratura italiana", 2, 1984, 3, pp. 519-554).

- Laura Battiferri Ammannati, Il primo libro delle opere toscane, a cura di Enrico Maria Guidi, Urbino, Accademia Raffaello, 2000.

- Benvenuto Cellini, Rime, a cura di Vittorio Gatto, Roma, Archivio Guido Izzi, 2001.

- Rime diverse (Giolito 1545), a cura di Franco Tomasi e Paolo Zaja, Torino, Res, 2001.

- Giovanni Della Casa, Rime, a cura di Giuliano Tanturli, Parma, Guanda (Fondaz. Bembo), 2001. 
- Poeti del Cinquecento, a cura di Guglielmo Gorni, Silvia Longhi, Massimo Danzi, Milano, Napoli, Ricciardi, 2001. - Serafino Aquilano, Strambotti, a cura di Antonio Rossi, Parma, Guanda, 2002.

- Luigi Cassola, Il canzoniere del codice Vaticano Capponiano 74, a cura di Giuliano Bellorini, Piacenza, Tip.Le.Co., 2002 ("Biblioteca storica piacentina" 14).

- Giovanni Della Casa, Rime, a cura di Stefano Carrai, Torino, Einaudi, 2003.

- Pietro Bembo, Stanze, a cura di Alessandro Gnocchi, Firenze, Società Editrice Fiorentina, 2003.

- Poetesse italiane del Cinquecento, a cura di Stefano Bianchi, Milano, Mondadori, 2003.

- Il "canzoniere" inedito del Domenichi 'mantovanizzatosi'. British Library, Add. 16557, a cura di Filippo Minetti, Pisa, ETS, 2003.

- Lodovico Domenichi, Rime, a cura di Roberto Gigliucci, Torino, Res, 2004.

- Anton Francesco Raineri, Cento sonetti, Torino, Res, 2004.

- Paride Ceresara, Rime, a cura di Andrea Comboni, Firenze, Olschki, 2004.

- Lirici europei del Cinquecento. Ripensando la poesia del Petrarca, a cura di Gian Mario Anselmi, Keir Elam, Giorgio Forni, Davide Monda, Milano, Rizzoli, 2004.

- Fausto Sozzini, Rime, a cura di Emanuela Scribano, Roma, Edizioni di Storia e Letteratura, 2004.

- Torquato Tasso, Rime. Prima parte - Tomo I. Rime d'amore (secondo il codice Chigiano L VIII 302), a cura di Franco Gavazzeni e Vercingetorige Martignone, Alessandria, Edizioni dell'Orso, 2004.

- Ludovico Martelli, Rime, a cura di Laura Amaddeo, Torino, Res, 2005.

- Berardino Rota, Egloghe pescatorie, a cura di Stefano Bianchi, Roma, Carocci, 2005.
Note-se, em particular, que foram três as antologias de lírica do século XVI a sucederem-se umas às outras, em quatro anos, desde a de 2000, organizada por quem escreve (La lirica rinascimentale); passando pela publicação do primeiro volume, que continua a ser o único, da antologia da Ricciardi em 2001 (Poeti del Cinquecento); até à ágil colectânea, mas rica, da Rizzoli (Lirici europei del Cinquecento), editada por ocasião do congresso de Bolonha. Uma notável fibrilhação, se se pensar que, anteriormente, a última operação antológica tinha sido a de Giulio Ferroni, em 1978, sendo necessário remontar, retrocedendo no tempo, a 1958 para a de Daniele Ponchiroli; a 1957 para a recolha básica de Luigi Baldacci; e a 1941 para a de Carlo Bo ${ }^{12}$. O volume do 'Poligrafico dello Stato' dedicado à Lirica rinascimentale é o único dos três organizado sob a égide de um único crítico, que é dizer, decorrente de propósitos de selecção e construção historiográfica arquitectonicamente estabelecidos, não sei com que resultados, espero profícuos. Além disso, o critério de ordenação não é geo-histórico, baseando-se antes em gerações. Pelo contrário, o monumental tomo da Ricciardi, que saiu exactamente um ano depois, fruto do trabalho que há décadas era levado a cabo por vários estudiosos, possui indubitáveis qualidades filológicas, que dele fazem um texto indispensável (pelo Bembo de Gorni e pelo Berni de Silvia Longhi, mas não só), apesar de mostrar, por vezes, limites de actualização

12 Vd., Lirici del Cinquecento, a cura di Carlo Bo, Milano, Garzanti, 1941; Lirici del Cinquecento, a cura di Luigi Baldacci, Milano-Napoli, Ricciardi, 1957, posteriormente, Milano, Longanesi, 1975; Lirici del Cinquecento, a cura di Daniele Ponchiroli, Torino, UTET, 1958, n. ed. a cura di Guido Davico Bonino, 1968; Poesia italiana del Cinquecento, a cura di Giulio Ferroni, Milano, Garzanti, 1978. (e vd. também a Antologia della poesia italiana, dir. da Cesare Segre e Carlo Ossola, 2, Quattrocento-Settecento, Torino, Einaudi, 1998, organizada com a colaboração de vários críticos; especificamente, a secção, "Petrarchisti e manieristi", é fruto do trabalho de Marco Ariani). 
bem patentes, sem que possa aspirar a uma interpretação global do fenómeno-petrarquismo. Objectivo esse visado, noutra perspectiva, pelos organizadores do volume da Rizzoli de 2004, em cujas páginas os poetas escolhidos se encontram dispostos segundo uma distribuição que é tanto geográfica, como formal, de modo a criar, na sua organização, um inquestionável efeito de riqueza, mas, além disso, um ecletismo que por vezes desorienta. Em todo o caso, trata-se de um instrumento muito inteligente e actualizado.

Em conclusão, face a tão significativa proliferação de edições, antologias e estudos sobre o petrarquismo, nestes últimos anos, o panorama geo-histórico e histórico-formal modificou-se? Tentemos propor uma sintética pontualização:

1. O modelo bembiano do classicismo vulgar mono-imitativo desfrutou de predominante importância na formação da língua comum que é o italiano literário, numa época em que a imprensa como medium ganhava crescente relevo.

2. O modelo bembiano não transformou, porém, a lírica do século XVI numa noite em que todos os gatos são pretos. O petrarquismo é plural ${ }^{13}$, compósito, por vezes feito de contrastes, sendo-o já no corpus das rimas de Bembo.

3. Entre os numerosos componentes e as numerosas instâncias que diversificam o petrarquismo a partir de dentro, há uma que é muito significativa e que está a ser objecto de novos estudos: a hibridação entre imitação petrarquesca e imitação dos clássicos.

4. Nessa linha, há que inserir um renovado interesse pela forma epigramática ${ }^{14}$, com as suas recaídas conceptuais, o so-

13 Há alguns anos que tenho vindo a insistir sobre o assunto. É a mesma a posição de Stefano Jossa no lúcido ensaio contido em, Nel libro di Laura, a cura di Luigi Collarile e Daniele Maira, Basel, Schwabe, 2004, pp. 91 ss.

${ }_{14}$ Giorgio Forni, Forme brevi della poesia. Tra Umanesimo e Rinascimento, Pisa, Pacini, 2001. neto e o madrigal, e, portanto, pelo determinante papel que desempenha enquanto ponto nodal conducente ao conceptismo maneirístico-barroco.

5. A categoria de Maneirismo lírico, cuja discussão também foi retomada no congresso de 2004 em Bolonha (com intervenções de Ezio Raimondi, Amedeo Quondam, Giulio Ferroni, Andrea Gareffi e outros), não perdeu préstimo, no mínimo pelo que diz respeito à poesia da segunda metade do século XVI. Trata-se de compreender o fenómeno na sua significação histórica, enquanto chave genealógica do moderno, perspectivando-o à luz da forte relação que mantém com o Barroco, no quadro da grande charneira europeia constituída pelos séculos XVI e XVII.

6. As mais recentes pesquisas em torno da gravitas $^{15}$ consentem uma descrição historiográfica cada vez mais definida e analítica da vertente lírica que vai da poesia 'cortesã' ao marinismo: o fenómeno de elevação do nível estilístico que se verifica em meados do século XVI e na segunda metade da centúria (do último Bembo a Della Casa e Tasso) mistura-se com a recuperação de motivos e imagens que eram próprios da lírica do tempo de Serafino Aquilano, mas com um novo nível de sublimação e elatio, facto não só formal, como ideológico, também por se situar após o aristocrático arranjo linguístico bembiano.

7. O petrarquismo será igualmente, e cada vez mais, motivo de observância, enquanto fenómeno sócio-antropológico de linguagem-espelho da comunidade dos cultos e dos civilizados. Aí reside a importância dos estudos sobre o petrarquismo de correspondência, que é dizer, sobre o relevo de que desfruta como circuito comunicativo, em sentido quer encomiástico, quer de relação inter pares.

15 Vd., por exemplo, Andrea Afribo, Teoria e prassi della "gravitas" nel Cinquecento, Firenze, Franco Cesati, 2001. 
8. O petrarquismo feminino, que desde sempre foi objecto de pesquisas específicas ${ }^{16}$, comporta uma interessante focalização não só sobre o sujeito da escrita, como também sobre o objecto de desejo lírico-amoroso, que são, pois, variantes internas no âmbito do sistema petrarquístico. Que não se esqueça, nessa economia, a lírica de amor homófilo, masculina e feminina, com as suas implicações classicísticas (modelos ovidianos, virgilianos, epigramáticos, etc.) e com o cunho transgressivo que lhe é próprio.

9. A distribuição geográfica do petrarquismo como critério ordenador e classificatório é sempre importante, mas deve ser temperada por elementos de compensação de sinal contrário, tais como: a 'comunhão' linguística do petrarquismo, sancionada, em termos gerais, pelas antologias coevas; a natureza nómade ou, pelo menos, as deslocações de alguns dos protagonistas (Della Casa veneziano, romano, toscano; Bernardo Tasso modelo para meridionais, tanto quanto para o público da planície do Pó, etc.).

10. Daqui decorre que o petrarquismo é fenómeno a ser estudado, cada vez mais, num quadro europeu: as investigações em torno das modalidades de recepção e transformação dos modelos italianos no estrangeiro ensinam-nos também muito acerca das diversas potencialidades e dos diferentes ânimos que fazem parte do nosso petrarquismo.

Naturalmente que estes são apenas alguns pontos de referência que se encontram na ordem do dia, por entre as novas rotas dos estudos sobre o petrarquismo. A abertura de horizontes, como em parte se viu, progrediu muito nos últimos anos. Nos venturos, mesmo que nos afastemos do ocasional umbigo do centenário, outras hipóteses não deixarão de ser confirmadas e renovadas e, sobretudo, os textos, em edições

${ }^{16}$ Vd., recentemente, "L'una et l'altra chiave". Figure e movimenti del petrarchismo femminile europeo, a cura di Tatiana Crivelli, Giovanni Nicoli, Mara Santi, Roma, Salerno, 2005. críticas, em edições comentadas, continuarão a ser publicados. Faltam à chamada, na verdade, muitos big: faltam edições de Domenico Venier, de Giovanni Guidiccioni, de Iacopo Marmitta, de Lodovico Paterno, de Celio Magno, de Luigi Groto, etc. Alguns destes autores e outros ainda estão a ser alvo de pesquisas filológicas que passarão ao prelo dentro de tempos supostamente breves. O trabalho interpretativo em torno da complexidade do petrarquismo, que deixou de ser redutível a uma etiqueta simplificadora usada nos manuais, será cada vez mais robusto. ${ }^{17}$

17 Para uma bibliografia entre 1989 e 2000, vd.: Giorgio Forni, Rassegna di studi sulla lirica del Cinquecento (1989-1999). Dal Bembo al Casa, "Lettere italiane", 52, 2000, pp. 100-140; Rassegna di studi sulla lirica del Cinquecento (1989-2000). II. Dal Tansillo al Tasso, "Lettere italiane", 52, 2000, pp. 422-461. 